\title{
Historia de ideas e historia de lenguajes políticas

\author{
Acerca del debate en torno a los usos de los \\ términos "pueblo" y "pueblos"*
}

\section{History of Ideas and History of Political Languages}

\section{On the discussion about the "pueblo" and "pueblos" concepts}

ELÍAS J. PALTI

Universidad Nacional de Quilmes(UNQUI), Argentina; Universidad Nacional de la Plata(UNPL); Consejo Nacional de Investigaciones Cientificas y Tecnicas(CONICET) Argentina Roque Sáenz Peña 180 - Bernal - B1876BXD - Buenos Aires, Argentina

RESUMO Los últimos veinte años han sido testigos de una transformación crucial en nuestros modos de concebir el proceso que llevaría a la quiebra del vínculo colonial con España. La visión dicotómica clásica que oponía el liberalismo latinoamericano al proverbial tradicionalismo y despotismo peninsular se habría tornado ya insostenible. Según han demostrado autores como François-Xavier Guerra, la crisis que conduciría a la independencia se trató de un proceso único, que comprendía de conjunto al Imperio, y que tenía, precisamente, su centro en la península, que será la más directamente afectada por la acefalía que entonces se produjo. Tal perspectiva nos abrirá una visión mucho más rica y compleja del proceso revolucionario hispanoamericano. Sin embargo, la quiebra de la oposición clásica liberalismo latinoamericano — tradicionalismo hispano se termina-

Artigo recebido em 14/02/2005. Autor convidado. 
rá resolviendo en una dicotomía inversa que opondrá ahora el liberalismo hispano al tradicionalismo latinoamericano. La persistencia de patrones sociales organicistas heredados de la Colonia, que harían de los "pueblos" (en plural), una vez caído el régimen monárquico, el depositario natural de la soberanía, impedirían aquí la emergencia de un concepto "moderno" de la nacionalidad como una entidad abstracta, homogénea y unificada. Como se intenta demostrar en el presente ensayo, esta visión debería, a su vez, revisarse a fin de desplegar las potencialidades implícitas para la escritura histórica en la profunda renovación teórico-metodológica que estos mismos autores produjeron en el campo.

Palavras-chave História, História Política, História da Linguagem

ABSTRACT The last twenty years witnessed a radical transformation in our ways of conceiving of the process leading to the break of the colonial tie with Spain. Classical dichotomous perspectives that opposed Latin American liberalism to Spanish despotism have proven untenable. As many authors, following François-Xavier Guerra, have showed, the crisis that resulted in independence was a single process, which comprised the Empire as a whole, and had its center, precisely, in the Spanish peninsula, which was more directly affected by the fall of the monarchy. Such a perspective opened the doors to a much richer and more replete view of the revolutionary process of independence in Latin America. However, the break of the classical opposition between Latin America liberalism and Spanish American despotism would ultimately resolve itself into the emergence of a converse dichotomy now opposing Spanish liberalism to Latin American traditionalism. The persistence of organic social patterns, inherited from the Colony, which made the pueblos (in the plural) of the Ancient Regime to become, after the fall of the monarchical system, the natural recipients of sovereignty, would prevent in the region the emergence of a modern concept of nationality as an abstract, homogeneous and unified entity. As the present essay intends to show, this view should be, in turn, revised in order to unfold all the potentialities for historical research implicit in the theoretical revolution that these very authors introduced in the field.

Key words History, Political History, History of Language

El cambio producido en esta rama de la historiografía en las dos décadas pasadas puede caracterizarse como un movimiento que lleva de enfatizar la historia del pensamiento (o, más crudamente, 'de ideas') a enfatizar algo diferente, para lo cual 'historia del habla' o 'historia del discurso', aunque ninguno de ellos carece de problemas o resulta irreprochable, pueden ser los mejores términos hasta ahora hallados.

\author{
J. G. A. Pocock, \\ Virtue, Commerce and History
}


El alumbramiento de un concepto de la "nacionalidad" será, como distintos autores señalan, un fenómeno tardío y sumamente complicado en América Latina. ${ }^{1}$ En principio, la lucha por la independencia se planteó exclusivamente en términos de un enfrentamiento entre "españolesamericanos" y "españoles-europeos", cada uno de ellos encarnando respectivamente los principios de la libertad versus los del despotismo. ${ }^{2}$ Según sus mismos actores, no se trataba tanto de una lucha nacional como de un enfrentamiento entre principios opuestos. Por los mismos no se definían aún criterios de identidad más allá de la espontánea adhesión a la causa de la independencia. La afirmación anterior debe, no obstante, matizarse. El hecho de que no existiera aún un concepto de la "nacionalidad" no quiere decir que no haya surgido un cierto sentido de "nación". De no ser así, la idea independentista habría sido simplemente inconcebible. Como pronto descubrirían los líderes patriotas, la sola invocación del principio de autodeterminación de los pueblos no alcanzaba para legitimar su secesión de la metrópoli. En contra de lo que algunos originalmente postularon, la crisis del orden monárquico no necesariamente tornaba inmediatamente evidente la idea del autogobierno de las colonias americanas.

En efecto, si bien las Cortes de Cádiz habían establecido el principio de que, en ausencia del monarca, la soberanía retrovertía en el pueblo, dicho principio dejaba aún indeterminado a qué pueblo se refería, cómo delimitar el mismo. Las nuevas autoridades revolucionarias, aun cuando gobernasen en nombre de Fernando VII, deberían poder justificar por qué una determinada sección del Imperio cabía considerarla portadora de una voluntad autónoma y separarse de la representación común expresada en las Juntas españolas (y luego en el Consejo de Regencia); en fin, por qué ciertas unidades administrativas - cualesquiera que éstas fueren - constituían auténticas "naciones" o "reinos" y en qué se distinguían éstas de las meras "regiones". Ello, sin embargo, se revelaría sumamente problemático.

Como muestra François-Xavier Guerra, este debate se planteó originariamente en términos de una oposición entre dos usos diversos del término "pueblo". Mientras que los americanos hablarían de "pueblos", en plural, los peninsulares adoptarían el término "pueblo", en singular. Por detrás de esta divergencia terminológica, Guerra percibe la presencia de dos imaginarios en conflicto. El uso en plural del término inscribía el discurso independentista en un marco de pensamiento tradicional, que

1 CHIARAMONTE, Véase José Carlos, El mito de los orígenes en la historiografía latinoamericana, en Cuadernos del Instituto Ravignani 2. Buenos Aires: Instituto de Historia Argentina y Americana "Dr. Emilio Ravignani", 1991.

2 "El triunfo de la libertad sobre el despotismo" (1817) era precisamente el título del libro del patriota venezolano Juan Germán Roscio. 
concebía al reino como organizado a partir de pluralidad de pueblos concretos, cada uno con sus derechos y obligaciones particulares derivados de vínculos contractuales y articulados por relaciones personales de vasallaje y subordinación que establecían una pirámide de potestades, la cual culminaba en el rey, en tanto que Señor natural del reino. El uso en singular del término que adoptan los liberales españoles es, por el contrario, síntoma inequívoco, para él, de la modernización de las referencias conceptuales, indica la emergencia de un concepto "moderno" de nación como una totalidad abstracta y unificada, compuesta de individuos originariamente libres y autónomos.

El presente trabajo se propone reconsiderar la postura de Guerra al respecto. Según se intentará demostrar, su intento de desarticular la antinomia tradicional entre liberalismo latinoamericano y despotismo hispano, marca un hito fundamental en la historiografía político-intelectual latinoamericana. Esto abre las puertas para comprender la serie de desplazamientos objetivos que, como resultado de la crisis del sistema monárquico, alterarían profundamente los lenguajes políticos. Sin embargo, lejos de llevar hasta sus últimas consecuencias la línea de análisis que a partir de allí se abre, termina cerrándola inmediatamente al colocar en su lugar una nueva forma, invertida, de antinomia que opondrá al liberalismo hispano el tradicionalismo latinoamericano. En definitiva, ello muestra que, más allá de la renovación conceptual que dicho autor produjo en la disciplina, seguía aferrado aún a los cánones de la vieja tradición de historia de "ideas".

\section{Pueblo, pueblos e imaginarios tradicionales}

En su oposición entre liberalismo hispano y tradicionalismo latinoamericano Guerra retoma, en realidad, uno de los tópicos clásicos de la historiografía española acerca del periodo gaditano, que destaca la impronta escolástica que tiñó el discurso de los diputados americanos, mucho más marcadamente que el de los peninsulares. ${ }^{3}$ Ya en $1947 \mathrm{Ma}-$ nuel Giménez Fernández afirmaba que "la base doctrinal y común de la insurgencia americana, salvo ciertos aditamentos de influencia localizada, la suministró no el concepto rousseauniano de Pacto social perennemente constituyente, sino la doctrina suareziana de la soberanía popular". ${ }^{4}$ Siguiendo esta tesis, Guerra señala que el tradicionalismo hispano-

3 Cfr. CHIARAMONTE, José Carlos, «Fundamentos iusnaturalistas de los movimientos de independencia», en Marta Terán y José Antonio Serrano Ortega, eds., La guerra de independencia en la América española. Zamora, Michoacán: El Colegio de Michoacán / Instituto Nacional de Antropología e Historia / Universidad Michoacana de San Nicolás de Hidalgo, 2002, p.99-123.

4 FERNÁNDEZ, Manuel Jiménez. Las doctrinas populistas en la independencia de Hispano-América. Sevilla: CSIC, 1947, p.29. 
americano se tradujo en una concepción pluralista de la nación como constituida por diversidad de "pueblos", en plural, impidiendo el desarrollo de estados modernos centralizados. Ahora bien, ¿puede tomarse el uso del término pueblos, en plural, como índice inequívoco de tradicionalismo cultural y social? ${ }^{5}$ Es posible que haya sido efectivamente así en este caso particular, pero no necesariamente. Esto sólo se puede establecer analizando cómo surgió, concretamente, la apelación americana al concepto pactista tradicional. ${ }^{6}$

Según surge de las fuentes, la visión plural del reino como articulada a partir de sistemas de subordinaciones tradicionales se impone en la diputación americana en el curso de la disputa suscitada por la designación de una gran cantidad de diputados suplentes residentes en España, debido a las dificultades de las colonias para enviar sus propios representantes, ${ }^{7}$ algo que aquellos cuestionarían dado que las poblaciones involucrados no habían participado de su elección ("diputados por voluntad ajena", Ios Ilamaba la Gaceta de Buenos Aires, elegidos "por un puñado de aventureros sin carácter ni representación"). ${ }^{8}$ La idea de una monarquía plural, conformada por diversidad de "pueblos" o "reinos", les permitiría entonces impugnar la capacidad de un "reino" de representar a otro (de acuerdo con el principio jurídico del negotiorum gestor). ${ }^{9}$ Frente a este argumento fue que los peninsulares postularon el concepto de una nación y una representación unificada, un único pueblo español, ${ }^{10}$ lo cual volvía relativamente indiferente el lugar concreto de residencia. ${ }^{11}$

A medida en que se avance en los debates, la postura de los diputados americanos se volverá, sin embargo, ambigua al respecto. El eje de la controversia pronto se desplazará hacia la proporcionalidad de la re-

5 Como vimos, una larga tradición de autores españoles hizo extensiva esta afirmación también a los liberales peninsulares, señalando sus raíces neoescolásticas, pero ello les sirve no para afirmar su tradicionalismo, sino, más bien, las raíces nativas del "primer liberalismo" español [véase AGESTA, Luis Sánchez. Historia del constitucionalismo españo. Madrid: Instituto de Estudios Políticos, 1955, 65-73].

6 Para estudios recientes sobre los debates gaditanos, y la participación de los americanos en ellos, véanse CHUST, Manuel. La cuestión nacional americana en las Cortes de Cádiz (1810-1814). Valencia: UNED / Historia Social / UNAM, 1999; RIEU-MILLAN, Marie. Los diputados americanos en la Cortes de Cádiz. Madrid: CSIC, 1998; y SUANCES-CARPEGNA, Joaquín Varela. La teoría del Estado en los orígenes del constitucionalismo hispánico (Las Cortes de Cádiz). Madrid: Centro de Estudios Constitucionales, 1983.

7 Por decreto del 8 de setiembre de 1810 a las provincias de Ultramar se le asignaron 30 representantes, sobre un total de 100. En el momento de reunirse las Cortes, 29 de ellos eran suplentes elegidos en Cádiz por 177 americanos residentes allí, y sólo uno, el representante de Puerto Rico, era titular. A medida en que llegaran los titulares, los suplentes deberían resignar su cargo, pero esto muchas veces será motivo de conflicto.

8 "Discurso sobre la nulidad de las Cortes que se celebran en España", Gaceta de Buenos Aires, 25 de febrero de 1811, citado por RIEU-MILLAN, Los diputados americanos en las Cortes de Cadiz, p.6.

9 Como afirmaba el peruano Ramón Feliú, la soberanía "se compone de partes real y físicamente distintas, sin las cuales todas, o sin muchas de las cuales no se puede entender la soberanía" (citado por RIEU-MILLAN, Los diputados americanos en las Cortes de Cádiz, p.15).

10 «Yo quiero que nos acordemos», insistía el diputado Diego Muñoz Torrero, «que formamos una sola Nación, y no un agregado de varias naciones» (Diario de Sesiones de las Cortes, 2 de setiembre de 1811).

11 En palabras de Jovellanos, «reuniendo en sí la representación nacional puede, sin duda, refundir una parte de ella en algunos de sus miembros» [JOVELLANOS, Melchor Gaspar de "Memoria», en Escritos políticos y filosóficos. Barcelona: Folio, 1999, p.187]. 
presentación (arts. 22 y 29). A las provincias de Ultramar se les otorgó una representación muy minoritaria, a pesar de que, según las estimaciones de la época, las dos secciones del imperio (España y América) contaban con una población equivalente. ${ }^{12}$ A esto se llegó mediante el expediente de excluir del censo a los miembros de las castas. Esta vez, los diputados americanos apelarán a un concepto moderno de la ciudadanía para protestar contra las desigualdades establecidas por el régimen electoral. ${ }^{13}$ En definitiva, hay que admitir que la "tesis épica" latinoamericana que destaca el liberalismo del pensamiento local frente al autoritarismo y tradicionalismo hispano no carece completamente de fundamentos. Al menos en este punto específico, que era el central para los americanos, éstos aparecían como más coherentemente liberales que los liberales peninsulares. ${ }^{14}$

Es cierto que todavía entonces su lenguaje combinará estos conceptos modernos con otros de matriz claramente pactista escolástica. Incluso puede aceptarse que estos últimos constituyeron su núcleo doctrinal. Aun así, está claro que sus cambiantes posturas obedecieron a una lógica estrictamente política, y su realineamientos ideológicos dependieron de cómo se planteó concretamente en cada caso el debate. Dada la posición en que se encontraban, la teoría pactista clásica aparecía sencillamente como la que mejor se ajustaba a sus objetivos estratégicos. Ésta, de hecho, les permitiría también abogar por la igualdad de la representación, al igual que la doctrina liberal, pero tenía sobre esta última una ventaja adicional fundamental: la invocación a los "pueblos", en plural, contenía en sí la amenaza apenas velada de una posible secesión por parte de las colonias ${ }^{15}$ (recordemos que los diputados americanos veían vicios de origen en las Cortes, y reiteradamente plantearon dudas respecto de la legitimidad de sus disposiciones sin previa consul-

12 Al respecto, véase RIEU-MILLAN. Los diputados americanos en las Cortes de Cádiz. Para una descripción detallada de las delegaciones americanas, véase María Teresa Berruezo, La diputación americana en las Cortes de Cádiz. Madrid: Centro de Estudios Constitucionales, 1986.

13 "Ser parte de la soberanía nacional", decía el mexicano José Simeón Uría, "y no ser ciudadano de la nación sin demérito personal, son a la verdad, Señor, dos cosas que no pueden concebirse, y que una a la otra se destruyen" (URÍA, Diario de Sesiones de las Cortes, 4 de setiembre de 1811). El mexicano Ramos Arizpe insistía al respecto: "V.N. tiene sancionado, con aplauso general, que la soberanía reside esencialmente en la nación [...]. Las castas como parte de la nación, tienen necesariamente una parte proporcional y respectiva de la soberanía" (ARIZPE, Ramos. Diario de Sesiones de las Cortes, 14 de setiembre de 1811).

14 Es sugestivo, al respecto, que los diputados americanos serán asociados a los sectores más radicales del liberalismo, encontrándose entre los que enfrentaron más denuncias y persecuciones luego de la restauración de Fernando VII.

15 "Es muy de temer", advertía el mexicano Ramos Arizpe, "que la aprobación del artículo en cuestión va a influir directamente en la desmembración de las Américas" (Actas de las Sesiones de Cortes, 5 de setiembre de 1811). Como reconocería luego Argüelles, «Era además una fatalidad inseparable de las circunstancias que acompañaron a la insurrección de la península el que la independencia de América se presentase a a imaginación de sus diputados no como un suceso eventual y remoto, sino como próximo e inevitable [...] Los diputados peninsulares no desconocían las causas que podían consumar algún día la separación absoluta de la América y las que conspiraban ahora a acelerarla». ARGÜELLES, Agustín. La reforma constitucional de Cádiz. Madrid: ITER, 1970, p.246-7. 
ta de las poblaciones americanas). ${ }^{16}$ Nada parece, en fin, autorizar ir más allá y pretender extraer de allí conclusiones respecto de la naturaleza social o identidad cultural de los sujetos involucrados. Debe recordarse, por otra parte, que su cohesión como grupo fue tal únicamente en lo relativo a la defensa de reclamos específicos para las colonias, pero que se trataba de una delegación ideológicamente heterogénea, que, en los demás puntos, se dividió internamente siguiendo las mismas líneas de escisión que dividieron al resto de los congresistas. ${ }^{17}$ Lo dicho, de todos modos, no se trata sólo de un recaudo metodológico; una operación intelectual tal (extraer conclusiones relativas a la naturaleza social o identidad cultural de los actores a partir de sus definiciones ideológicas) conlleva una serie de supuestos relativos a los modos de concebir la historia intelectual que, como veremos, se han vuelto hoy difíciles de sostener (y, en definitiva, nos devuelven a la vieja historia de "ideas"). Esto se observa más claramente cuando analizamos el otro polo de la antinomia que establece Guerra.

Como vimos, el motor de la mutación cultural que se produjo en el lapso de esos "dos años cruciales" fue, según afirma, el grupo liberal encabezado por Quintana. Esta evolución, sin embargo, tuvo efectos contradictorios para España puesto que selló su divorcio respecto de América. "Las Cortes de Cádiz", asegura Guerra, "al hacer de la nación española un Estado unitario cerraban definitivamente la posibilidad de mantener a los reinos de Indias en el seno de la Monarquía". ${ }^{18}$ Así como el particularismo americano revelaba, para Guerra, un imaginario tradicionalista, inversamente, el ideal liberal de una nación unificada impuso una política cerradamente "colonialista" (entendido esto en el sentido de

16 El propio diputado peninsular y líder del partido constitucionalista histórico, Francisco Martínez Marina, reconocería luego esta deficiencia de origen, proponiendo una nueva convocatoria. De hecho, no sólo las provincias ultramarinas habían tenidos problemas para participar de las Cortes, sino también las provincias ocupadas de España. «Muchas provincias de España y las principales de la corona de Castilla», decía, «no influyeron directa ni indirectamente en la constitución, porque no pudieron elegir diputados ni otorgarles suficientes poderes para llevar su voz en las cortes, y ser en ellas los intérpretes de la voluntad de sus causantes. De que se sigue, hablando legalmente y conforme á reglas de derecho, que la autoridad del congreso extraordinario no es general, porque su voz no es el órgano ni la expresión de la voluntad de todos los ciudadanos, y por consiguiente antes de comunicar la constitución á los que tubieron parte en ella y de exigirles el juramento de guardarla, requería la justicia y el derecho que prestasen su consentimiento y aprobación lisa y llanamente, ó proponiendo modificaciones y reformas que les pareciese por medio de diputados libremente elegidos y autorizados con suficientes poderes para entender en este punto y en todo lo actuado en las cortes». MARINA, Francisco Martínez. Discurso sobre el origen de la monarquía y sobre la naturaleza del gobierno español. Madrid: Centro de Estudios Constitucionales, 1988, p.165-6.

17 Como afirma Rieu-Millan, "no se observa una relación aparente entre el 'americanismo' de estos diputados y su ideología política: liberales más o menos moderados, conservadores ilustrados, absolutistas" (RIEU-MILLAN, Los diputados americanos en las Cortes de Cádiz, p.374). Muchos de sus miembros, además, mantuvieron posturas oscilantes en cuanto a sus adhesiones partidarias. Fray Servando Teresa de Mier, por ejemplo, admitía, en momentos en que se declaraba conservador, haber tenido un periodo jacobino en tiempos en que escribió sus "Cartas a El Español". De hecho, es difícil hablar, para este periodo temprano, de "partidos" o aun de corrientes ideológicas claramente definidas. Al respecto, véase el interesante artículo de BREÑA, Roberto. "Un momento clave en la historia política moderna de la América hispana: Cádiz, 1812", manuscrito.

18 François-Xavier Guerra, Modernidad e independencias. Ensayos sobre las revoluciones hispánicas. México: MAPFRE / F.C.E., 1993, p.341. 
que llevaría a rechazar de plano los reclamos de mayor autonomía de las colonias). "Para establecer una verdadera igualdad política entre las dos partes de la Monarquía", asegura, "hubiera sido preciso transformar el imaginario de las élites peninsulares". ${ }^{19}$ Sin embargo, si analizamos esta afirmación, se observa en ella una inversión de las relaciones de causalidad. De ningún modo puede atribuirse el carácter colonialista de la postura de la mayoría peninsular a sus ideas liberales; en todo caso, sería mucho más correcta la afirmación inversa de que, si abrazaron en este punto una visión moderna de Nación, fue porque la misma armonizaba con sus posturas colonialistas. Lo cierto, sin embargo, es que no existe una correlación necesaria entre ambos términos (liberalismo y coIonialismo). Lo demuestra el hecho de que colonialistas fueron por igual tanto los liberales como los absolutistas. ${ }^{20}$ Inversamente, si bien el liberalismo servía perfectamente de sustento ideológico al colonialismo, era, no obstante, igualmente compatible con una postura opuesta. De hecho, como vimos, también los diputados americanos apelaron a premisas liberales a fin de afirmar su demanda de representación igualitaria. El propio Guerra se contradice en este punto al admitir que, el hecho de abogar por la igualdad de representación, obligaba a los americanos adherir a ese mismo ideal liberal que, según afirma, llevaba a los peninsulares a rechazar todo reclamo en este sentido.

Su objetivo fundamental fue en este caso, batallar por la igualdad de representación entre España y América. Era éste su objetivo prioritario, lo que en parte explica que, a pesar de su concepción plural de la Monarquía, aceptasen los planteamientos de los liberales peninsulares. La petición de igualdad con la Península y la obtención del elevado número de diputados que esto llevaba consigo, les hacía aceptar entonces una concepción unitaria de la Monarquía que cuadraba mal con su muy enraizada visión de ésta como un conjunto de comunidades políticas diferentes. ${ }^{21}$

En realidad, tampoco esto era exactamente así. Como afirma RieuMillan con relación al principio de soberanía popular, "esta defensa podía fundamentarse, en otro contexto, sobre bases teóricas tradicionales (estado patrimonial compuesto por diferentes reinos)". ${ }^{22}$ Esto muestra las complejidades del debate, y la imposible reducción mutua entre imaginarios sociales e ideologías políticas determinadas. En fin, si la antino-

19 GUERRA. "La desintegración de la Monarquía hispánica". In: ANNINO, Antonio, LEIVA Luis Castro y GUERRA, François-Xavier. (comps.) De los imperios a las naciones. Iberoamérica. Zaragoza: Ibercaja, 1994, p.225.

20 Guerra está aquí, en realidad, polemizando, al mismo tiempo, con una larga tradición historiográfica que ve el origen de la disolución del imperio en la visión conservadora de España, que, según señala Álvarez Junco, concebía la misma como "una nación única, antigua, castellanizada y homogénea", consustancial por ello "con la monarquía, con la religión católica y con un estado fuertemente centralizado y con vocación uniformista" JUNCO, José Álvarez. Mater Dolorosa. La idea de España en el siglo XIX. Madrid: Taurus, 2001, p.27.

21 GUERRA. Modernidad e independencias, p.345.

22 RIEU-MILLAN. Los diputados americanos en las Cortes de Cádiz, p.17. 
mia "liberales peninsulares = atomicismo = colonialismo" versus "tradicionalismo americano = organicismo = independentismo" puede aceptarse como una descripción correcta del modo en que se alinearon las fuerzas en Cádiz, está claro que tal contraposición no se funda en ningún nexo conceptual (ni la defensa americana de una concepción plural de la monarquía era, en sí misma, "tradicional", ni la idea moderna de una nación unificada era necesariamente colonialista), sino uno puramente contingente, derivado de las circunstancias y las formas en que se fijó el debate y se establecieron eventualmente líneas de alianza y ruptura en las Cortes mismas. ${ }^{23}$

Volviendo, pues, a nuestra pregunta original: ¿hasta qué punto la apelación a las doctrinas neoescolásticas representaba verdaderamente un regreso a un tipo de imaginario tradicional? Como señalamos, determinar esto de un modo preciso resulta imposible. En realidad, distinguir los motivos "tradicionales" y "modernos" ni siquiera es siempre factible. Éstos se mezclan de modos cambiantes y complejos en el discurso político del periodo, al punto de volverse muchas veces indiscernibles. Y ello no tanto debido a ambigüedades propias al discurso político latinoamericano del periodo, al uso incierto u oscilante de que fueron objeto dichos conceptos, su alegada "hibridez", como de aquellas, más fundamentales, inherentes a esos mismos conceptos. Esto se observa aún más claramente cuando analizamos el discurso independentista.

\section{Pueblo y pueblos en el discurso de la emancipación}

Según señala Antonio Annino, el porteño Mariano Moreno es el mejor ejemplo de la emergencia temprana de un concepto de nacionalidad unificada, esto es, del virreinato como "una unidad indestructible", en contraposición con la idea de la misma como una mera agregación de pueblos. ${ }^{24}$ Como afirma en un documento aparecido originalmente en 1810 en forma serializada en La Gaceta de Buenos Aires, "Sobre la misión del Congreso", ${ }^{25}$ "la verdadera soberanía de un pueblo nunca ha consistido sino en la voluntad general del mismo", la cual, asegura, es "indivisible e inalienable". ${ }^{26}$ Incluso puede allí descubrirse en su base un con-

23 En verdad, si bien el colonialismo de los diputados peninsulares no necesariamente contradecía su liberalismo, les plantearía sí contradicciones políticas reales serias, desde el momento que los obligaba a aliarse a los sectores ultrarrealistas en América. Los diputados americanos en Cádiz les obligarían a enfrentarse una y otra vez a esta contradicción, llevando propuestas de remoción de los virreyes Abascal de Perú y Venegas de México, por desconocer las sanciones constitucionales. Éstos aparecerían como baluartes del absolutismo, al que los liberales despreciaban, pero, por otro lado, constituían los pilares fundamentales, en sus respectivas regiones, del orden colonial que ellos también defendían, o no estaban dispuestos a alterar.

24 ANNINO. "Soberanías en lucha". In: ANNINO et al. De los imperios a las naciones, p.249.

25 Su título completo es: "Sobre la misión del Congreso convocado en virtud de la resolución plebiscitaria del 25 de Mayo", y se encuentra en MORENO, Mariano. Escritos políticos y económicos. Buenos Aires: La Cultura Argentina, 1915, p.269-300.

26 MORENO. "Sobre el Congreso convocado". In: Escritos políticos y económicos, p.284. 
cepto individualista de lo social. "En esta dispersión", insiste Moreno, "no sólo cada pueblo asumió la autoridad que de consuno habían conferido al monarca, sino que cada hombre debió considerarse en el estado anterior al pacto social". ${ }^{27}$ Con esta definición, sin embargo, Moreno se apartaría del consenso dominante. Annino cree hallar allí, en fin, el origen de la lucha que signaría toda la historia argentina subsecuente: "las soberanías de los pueblos", dice, "se contrapondrán durante largo tiempo a la soberanía del pueblo o de la Nación" proclamada por Moreno. ${ }^{28}$

De acuerdo con el modelo de Guerra, habría, pues, que considerar a Moreno como un claro vocero de la idea moderna de nación, frente a una sociedad aferrada aún a una concepción tradicional de la misma. Esto, sin embargo, no era necesariamente así. La idea de Moreno de pueblo podía perfectamente enmarcarse en los cuadros de una visión todavía corporativa, esto es, asociarse a la preeminencia que gozaba Buenos Aires, en tanto que capital virreinal, dentro de la pirámide de jerarquías tradicionales entre ciudades. De hecho, dichos imaginarios tradicionales no carecían de un principio que permitiera articular entidades políticas suprarregionales, es decir, que pudiera funcionar como fundamento a un cierto concepto de nación unificada sirviendo así de concepto bisagra entre dos lenguajes políticos contrapuestos: el principio jurídico de negotiorum gestor (la facultad de una parte del reino de representar la totalidad).

Éste fue, de hecho, el principio que invocó el Cabildo porteño para arrogarse la representación del conjunto del virreinato, y justificar así su desconocimiento de las autoridades peninsulares. Sin embargo, Moreno rechazaría explícitamente el mismo. Según descubre, buscando justificar su causa, con tal invocación el Cabildo había incurrido en una obvia contradicción, dado que éste era, precisamente, el principio en que la Junta gaditana fundaba también su legitimidad. Tal comprobación lo devuelve, pues, a un concepto más "tradicional": la legitimidad de las nuevas autoridades sólo podría fundarse en el asentimiento de los "pueblos". El Congreso convocado de que habla el artículo que analizamos debía, justamente, servir de ejemplo al conjunto del imperio ("ha sido este un acto de justicia", decía, "de que las capitales de España no nos dieron ejemplo, y que los pueblos de aquellas provincias mirarán con envidia"). ${ }^{29}$

La postura de Moreno, cabe aclarar, resulta aún entonces oscilante en este punto, lo cual la propia ambigüedad del término hace posible. La frase con que concluye dicho documento es ilustrativa al respecto. Lue-

27 MORENO. "Sobre el Congreso convocado". In: Escritos políticos y económicos, p.284.

28 ANNINO. "Soberanías en lucha". In: Annino et al. De los imperios a las naciones, p.251.

29 MORENO. "Sobre el Congreso convocado". In: Escritos políticos y económicos, p.283. 
go de comprobar que "es una quimera que todas las Américas españolas formen un solo Estado", asegura:

Puede, pues, haber confederación de naciones, como la de Alemania, y puede haber federación de una nación, compuesta de varios estados soberanos, como la de Estados Unidos. Este sistema es el mejor, quizá, pero difícilmente podrá aplicarse a toda la América. /.../ Yo desearía que las provincias, reduciéndose a los límites que hasta ahora han tenido, formasen separadamente la constitución conveniente a la felicidad de cada una. ${ }^{30}$

Los "pueblos" a los que se refiere, pues, son siempre aquellos de las "provincias". Pero la idea de "provincia" no tenía un significado fijo. Ésta designaba simplemente una parte de una unidad política mayor. Cuando se refería al virreynato, indicaba vagamente lo que hoy entendemos por provincias, pero, cuando se refería al imperio o a América en su conjunto, como es el caso de la cita anterior, las provincias aludidas eran, en cambio, los virreinatos (es decir, algo mucho más cercano a lo que hoy solemos designar como "naciones").

Es cierto, de todos modos, que, desde el momento en que rechaza el principio de negotiorum gestor, deberá, a su vez, trasladar este mismo concepto federativo al interior de cada uno de los virreinatos, provocando la fragmentación de la soberanía en sus componentes elementales (i.e., las provincias, esta vez entendidas como las secciones de las cuales está constituido cada virreinato). El punto es que, al igual que en el caso de la diputación americana en Cádiz, dicha postura respondió a consideraciones políticas precisas. En el interior del universo de ideas tradicional no había ninguna razón conceptual que impidiera la postulación de entidades políticas suprarregionales, como los virreinatos, como sujetos legítimos de la imputación soberana.

Podemos ver que, así como la noción de "pueblos", en plural, no era necesariamente tradicional, inversamente, tampoco la sola aparición del término "pueblo", en singular, prejuzgaba respecto de su contenido, es decir, no remitía ineludiblemente a un horizonte moderno de pensamiento. De hecho, sus orígenes remotos pueden rastrearse en la referencia bíblica al pueblo israelí, la cual servirá de modelo para toda concepción de comunidad unitaria. Ciertamente, estamos muy lejos aún de una idea moderna del mismo, asociada al de nación (también en el sentido moderno del término). Dicho término se conectaba todavía con el de ecclesia cristiana y, posteriormente, con el del corpus mysticum encarnado en el soberano (o, eventualmente, en el Parlamento, idea que, a su vez, retomaría la tradición conciliar elaborada en tiempos del Gran Cisma y

30 MORENO. "Sobre el Congreso convocado". In: Escritos políticos y económicos, p.300. 
en la cual se basó el colegio cardenalicio para disputar con el Papa el papel de representante de Dios en la Tierra). ${ }^{31}$ No viene al caso aquí seguir los detalles de su trayectoria; baste señalar el hecho de que identificar los horizontes conceptuales en que se inscribe un discurso político dado no resulta tan sencillo como aquella oposición sugiere. Y esto nos plantea una cuestión más vasta, de orden epistemológico.

La perspectiva de Guerra que imagina los cambios político-conceptuales como el resultado del desplazamiento de un universo categorial por otro distinto que súbitamente emerge, la lucha entre dos horizonte claramente delimitados y opuestos entre sí, traza un cuadro algo simplista de los modos en que se producen las mutaciones conceptuales. Como señalan estudiosos de los lenguajes políticos como J. G. A. Pocock y Quentina Skinner, si bien la dinámica de los cambios en los mismos conlleva rearticulaciones drásticas de sentido, las novedades lingüísticas siempre deben aún legitimarse según los lenguajes preexistentes. Y esto nos enfrenta ante la paradoja de cómo conceptos inasimilables dentro de su universo semántico pueden, no obstante, resultar comprensibles y articulables dentro del vocabulario disponible (puesto que de lo contrario no podrían circular socialmente); cómo éstos se despliegan en el interior de su lógica, socavándola. En La génesis de la revolución copernicana, Hans Blumenberg nos ofrece algunos ejemplos de ello. ${ }^{32}$

Según muestra dicho autor, la astronomía copernicana necesariamente se levanta a partir de las premisas del pensamiento escolásticomedieval y entronca con él. Éste aporta, en definitiva, el bagaje categorial que, por un lado, Copérnico encuentra disponible a fin de imaginar un universo en el que nuestro planeta aparezca desplazado a un lugar excéntrico al mismo, así como, por otro lado, regula los criterios de aceptabilidad de dicha nueva doctrina. ${ }^{33}$ De hecho, señala, la cosmología copernicana surge más bien de un intento de salvar la física aristotélica que de alguna vocación por destruir la misma. Sin embargo, y a pesar de ello, termina utilizando los mismos principios aristotélicos para subvertir su concepción física en su propia base. ${ }^{34}$ Para que ello resultara posible fue necesario antes, sin embargo, un proceso de aflojamiento de su sistema que abriera aquella latitud (Spielraum) en la cual la revolución copernicana se volviera concebible; aunque no por ello la anticipaba. ${ }^{35} \mathrm{La}$

31 La tradición conciliar buscaba de este modo un instrumento que protegiera a la Iglesia ante la posibilidad de un Papa hereje. Skinner encuentra aquí el origen remoto de las ideas pactistas modernas [véase SKINNER, Quentin. The Foundations of Modern Political Thought. Cambridge: Cambridge University Press, 1988, p.114123].

32 Véase BLUMENBERG. Hans. Die Genesis der kopernikanischen Welt. Francfort: Suhrkamp, 1996.

33 BLUMENBERG. Die Genesis der kopernikanischen Welt, p.155.

34 De este modo, Blumenberg se distanciaría tanto de las versiones "vulcanistas" (que imaginan las rupturas conceptuales como abruptas reconfiguraciones de sentido) como "neptunianas" (que ven las mismas como el resultado de un largo proceso de transformaciones graduales).

35 BLUMENBERG, Die Genesis der kopernikanischen Welt, p.158. 
trayectoria de la inflexión de la que nace la física moderna ilustraría así lo que llama la historia de efectos (Wirkungsgeschichten) por la cual un nuevo imaginario cobra forma.

La ruptura conceptual que venimos analizando cabría igualmente entenderla como una historia de efectos. Esta perspectiva expresa mejor la serie de desplazamientos por los cuales se fueron entonces torsionando los lenguajes, cómo formas de discurso radicalmente incompatibles con los imaginarios tradicionales nacerían, sin embargo, de recomposiciones operadas a partir de sus propias categorías. La idea de la yuxtaposición de ideas tradicionales y modernas brinda una imagen, si no desacertada, sí algo pobre y deficiente de los fenómenos de trastrocamiento de los vocabularios políticos, puesto que no alcanza aún a comprender esa paradoja de cómo nuevos horizontes conceptuales irrumpen en el seno de los viejos, se despliegan y encadenan desde el interior de su misma lógica, al mismo tiempo que la desarticulan. El artículo de Mariano Moreno que venimos analizando sirve también de punto de partida para observar el complicado proceso de recomposición semántica que supuso la afirmación de un concepto «moderno» de nación.

\section{La nación como problema}

La apelación de Moreno a los «pueblos» como sede originaria de la soberanía tiene implícita una impugnación radical de la autoridad real. Para él, no se trata simplemente de que la ausencia del rey haya hecho desaparecer el pacto de sujeción que ligaba a las colonias con el monarca. Dicho pacto, afirma, en realidad nunca había tenido lugar. El origen del dominio real sobre América asegura que no estuvo nunca fundada en el consentimiento de los pueblos, sino en un acto de violencia. ${ }^{36}$ Era, por lo tanto, absolutamente ilegítimo. De allí deriva una consecuencia más fundamental: en esta parte del reino, "el que subrogue por elección del Congreso la persona del Rey, que está impedida de regirnos, no tiene reglas por donde conducirse, y es preciso prefijárselas". ${ }^{37}$ "Esta obra", asegura, "es la que se llama constitución del Estado". ${ }^{38}$ La vacatio regis en América desnudaba así otra vacancia más fundamental, la vacatio legis. Aquí, pues, no se trataría tan sólo de establecer una nueva autoridad que llene el lugar vacante del soberano, sino que habría que crear una legitimidad inexistente, constituir el or-

36 "La América en ningún caso puede considerarse sujeta a aquella obligación; ella no ha concurrido a la celebración del pacto social de que derivan los monarcas españoles, los únicos títulos de legitimidad de su imperio; la fuerza y la violencia son la única base de la conquista" (MORENO. "Sobre el Congreso convocado". In: Escritos políticos y económicos, p.290).

37 MORENO. "Sobre el Congreso convocado". In: Escritos políticos y económicos, p.287.

38 MORENO. "Sobre el Congreso convocado". In: Escritos políticos y económicos, p.286. 
den político. Todo su discurso se encuentra impregnado de un sentido de refundación radical. ${ }^{39}$

El radicalismo de Moreno, indisputable desde el punto de vista político, es menos evidente, sin embargo, cuando se lo considera desde una perspectiva histórico-conceptual. Sin embargo, no es en su concepto plural del imperio en donde radica su mayor limitación. Paradójicamente, es la misma premisa que, como señala Annino, marca la modernidad de su concepto (la idea de una soberanía nacional que preexiste a la autoridad política) la que le impide avanzar hacia aquel punto en que la ruptura con los imaginarios tradicionales se volvería ya irreversible.

En efecto, para Moreno, que hubiera que constituir a la nación significaba que el Congreso convocado no sólo debía designar quién habría de gobernar, sino también cómo habría de hacerlo, fijar el marco legal dentro del cual habría de ejercer su poder. Pero ello presuponía ya la existencia de aquella entidad a la cual se invocaba, justamente, para hacer tal convocatoria. Según aclaraba inmediatamente a continuación de la cita antes transcripta, en la que afirmaba que aquella reversión soberana se aplicaba no sólo el pueblo, en su conjunto, sino también a cada individuo,

No pretendo con esto reducir los individuos de la Monarquía a la vida errante que precedió a la formación de las sociedades. Los vínculos que unen el pueblo al rey, son distintos de los que unen a los hombre entre sí mismos: un pueblo es un pueblo antes de darse un rey. ${ }^{40}$

Aunque las relaciones sociales entre los pueblos y el Rey quedasen disueltas o suspensas por el cautiverio de nuestro monarca, los vínculos que unen a un hombre con otro en sociedad quedaron subsistentes, porque no dependen de los primeros; y los pueblos no debieron formarse pueblos, pues ya lo eran, sino de elegir una cabeza que los rigiese, o regirse a sí mismos, según las diversas formas con que puede constituirse íntegramente el cuerpo moral. ${ }^{41}$

Por entonces, sin embargo, los primeros síntomas de disenso interno comenzarían a plantear aquella cuestión más fundamental interdicta en su discurso, puesto que constituía su premisa.

Es digno de observarse - señalaba - que entre los innumerables jefes que de común acuerdo han levantado el estandarte de la guerra civil para dar en tierra la justa causa de la América, no hay uno solo que limite su oposición al

39 "Pocas veces ha presentado el mundo un teatro igual al nuestro, para formar una constitución que haga felices a los pueblos"; "Ia América presenta un terreno limpio y bien preparado", insistía, "donde producirá frutos prodigiosos la sana doctrina que siembren diestramente los legisladores". (MORENO. "Sobre el Congreso convocado". In: Escritos políticos y económicos, p.270).

40 MORENO. "Sobre el Congreso convocado". In: Escritos políticos y económicos, p.279.

41 MORENO. "Sobre el Congreso convocado". In: Escritos políticos y económicos, p.279. 
modo o a los vicios que pudiera descubrir en nuestro sistema; todos lo atacan en la sustancia, no quieren reconocer derechos algunos a la América. ${ }^{42}$

La perspectiva de una guerra civil revelaría que lo que se encontraba entonces en disputa no era quién y cómo habría de gobernar, sino, fundamentalmente, a quién habrá de hacerlo (al conjunto de los súbditos del monarca, o a alguna sección particular de ellos), y, en definitiva, quién podría determinarlo. Encontramos aquí el punto que marca la dinámica diferencial entre la península y sus colonias. El verdadero núcleo que subyace y motoriza el proceso de reconfiguración de los lenguajes políticos en la región no es tanto, o solamente, la vacancia del poder, ni tampoco, ciertamente, la lucha contra el ocupante extranjero, sino el profundo antagonismo que entonces desgarraría a la sociedad local en bandos mortalmente enfrentados. La misma se vería así súbita e ineluctablemente arrojada al reino de la política. La guerra contra el enemigo externo se convertiría aquí en guerra civil, quebrando todo principio de representación. Y esto nos devuelve a aquel aspecto que todos los matices necesarios que introdujo Guerra hicieron, sin embargo, desdibujar, que consiste, más allá de la supuesta mayor persistencia de imaginarios tradicionales, del carácter revolucionario del proceso a partir del cual se fundarían los nuevos estados nacionales. Este mismo hecho obligaba a confrontar una serie de cuestiones que simplemente resultaban ininteligibles en los marcos del pactismo clásico, pero que tampoco se plantearían en esos años en la península. La nación dejaría entonces de ser el punto de partida y la premisa en la que descansaba el discurso independentista para convertirse ella misma en un problema.

\section{Conclusión: De las “ideas” a los "lenguajes políticos”}

En definitiva, Guerra pierde de vista el sentido último de la transformación metodológica que viene experimentando la disciplina en el curso de los últimos veinte años. Éste se propone reconstruir lenguajes políticos, pero sigue pensando los mismos como sistemas de ideas. Un lenguaje, a diferencia de las ideas, no es un atributo subjetivo. Mientras que las ideas remiten a la conciencia de los sujetos y son relativas a los mismos, los lenguajes son entidades objetivas, se encuentran públicamente disponibles, para diversos usos posibles, por distintos interlocutores. Los vocabularios de base no cambian con las posturas de sus portadores, sino que definen las coordenadas dentro de las cuáles éstas pueden eventualmente desplazarse (al menos, sin hacer entrar en crisis el mismo). De allí que los giros en la trayectoria ideológica - siempre ine-

42 MORENO. "Sobre el Congreso convocado". In: Escritos políticos y económicos, p.295. 
vitablemente errática y cambiante - de los actores políticos no siempre sirvan de guía para reconocer cambios operados al nivel de los lenguajes subyacentes, e, inversamente, la persistencia de ciertas tendencias ideológicas dominantes bien puede ocultar una recomposición profunda de las condiciones de enunciación de los discursos. La referencia que hace Guerra a Tocqueville es particularmente significativa al respecto.

Retomando una comparación planteada por Federico Suárez, Guerra afirma que, "como lo hizo notar Tocqueville, a propósito de la idéntica consulta que en Francia hizo Lomenie de Brienne en 1788, al hacer de la constitución un tema de debate se pasa, ya, de la restauración de las leyes fundamentales a la política moderna, al reino de la opinión". ${ }^{43}$ En efecto, la emergencia de la "política moderna" refiere, concretamente, a qué se va entonces a debatir. Son los cambios en las preguntas que se plantean los que señalan desplazamientos en las coordenadas conceptuales, trastrocando los vocabularios de base. Ésta es también, de hecho, la premisa sobre la cual se funda la perspectiva de Guerra, ${ }^{44}$ el núcleo fundamental de su empresa renovación historiográfica. Sin embargo, se muestran aquí también las vacilaciones de su método. La interpretación que ofrece inmediatamente a continuación contradice, en realidad, este postulado.

Los acontecimientos posteriores confirman esta intuición. Los resultados de la consulta - conocidos en buena parte de España y en una debilísima parte de América - muestran cómo, aunque el constitucionalismo histórico es aún fuerte, los liberales van ganando terreno..$^{45}$

Guerra extrae, pues, de la afirmación de Tocqueville la conclusión de que "la victoria de los revolucionarios es consecuencia de la victoria ideológica, de la que es un signo inequívoco e irreversible de la mutación del lenguaje". ${ }^{46}$ Identifica así tal mutación "irreversible" del lenguaje con un giro ideológico: el avance del ideario liberal y el retroceso del constitucionalismo histórico. Sin embargo, está claro que no era eso lo que planteaba Tocqueville. Lo que señalaba éste era, precisamente, que

43 GUERRA. "La política moderna en el mundo hispánico: apuntes para unos años cruciales (1808-1809)". In: PALAFOX, Ricardo Ávila, ASSAD, Carlos Martínez y MEYER, Jean. (coords.) Las formas y las políticas del dominio agrario. Homenaje a François Chevalier. Guadalajara: Universidad de Guadalajara, 1992, p.178.

44 «Aunque, por el momento», afirma, «tanto las Cortes y la representación americana en la Junta Central se concibe aún en el marco de la representación tradicional — representación de los «pueblos», que se expresan por sus cuerpos municipales - los temas de los que se va a discutir en adelante son los temas claves que abren la puerta a la revolución política y a la Independencia americana. De lo que se va a debatir realmente durante los años siguientes, a través de las modalidades prácticas de la representación, es: ¿qué es la nación?» (GUERRA. Modernidad e independencia, p.133).

45 GUERRA. "La política moderna en el mundo hispánico". In: PALAFOX, Ricardo Ávila, ASSAD, Carlos Martínez y MEYER, Jean. (coords.) Las formas y las políticas del dominio agrario, p.178.

46 GUERRA. "La política moderna en el mundo hispánico In: PALAFOX, Ricardo Ávila, ASSAD, Carlos Martínez y MEYER, Jean. (coords.) Las formas y las políticas del dominio agrario, p.179. 
el sólo llamado a las Cortes había marcado una ruptura fundamental, independientemente de quién ganase luego la elección o qué ideas se impusiesen. De hecho, no habría sido impensable que los constitucionalistas históricos, o incluso los absolutistas, triunfasen en las mismas, pero ello no habría alterado el hecho de fondo para Tocqueville: que la constitución se había vuelto objeto de debate público. Era este hecho, no el posterior triunfo del partido liberal, lo que transformaría de un modo irreversible los lenguajes políticos. Y ello porque el mismo reconfiguraría radicalmente el terreno de debate.

Este problema se expresa aun más crudamente cuando analiza el discurso independentista, en la medida en que lleva a perder de vista cómo, más allá del supuesto mayor tradicionalismo de los latinoamericanos, de la persistencia de ideas, la ruptura del vínculo colonial alteraría, aún de un modo más drástico, los lenguajes políticos. En efecto, en las colonias habría entonces de emerger aquella pregunta que no tenía todavía un lugar concebible en el universo de cuestiones que se planteara el primer liberalismo hispano (y que Guerra pierde de vista). Según señala este autor, para los liberales gaditanos «se trata de fundar una nación y de proclamar su soberanía y de construir a partir de ella, por la promulgación de una constitución, un gobierno libre». ${ }^{47}$ Sin embargo, la idea de un poder constituyente refería estrictamente a la facultad de establecer o alterar el sistema de gobierno. El art. 3 de la Constitución antes citado, en su redacción original, hacía esto explícito: «La soberanía», decía, «reside esencialmente en la Nación, y por lo mismo le pertenece exclusivamente el derecho de establecer sus leyes fundamentales, y de adoptar la forma de gobierno que más le convenga». ${ }^{48}$ El nuevo pacto social refundaría el Estado, pero ello presuponía ya la Nación que pueda hacer esto. Las declaraciones de Juan Nicasio Gallego muestran claramente esta doble dimensión del concepto:

Una nación — dice Gallego - , antes de establecer sus leyes constitucionales y adoptar una forma de gobierno es ya una nación, es decir, una asociación de hombres libres que han convenido voluntariamente en componer un cuerpo moral, el cual ha de regirse por leyes que sean el resultado de la voluntad de los individuos que lo forman y cuyo único objeto es el bien y la utilidad de toda la sociedad. ${ }^{49}$

La idea de la preexistencia de la nación era, en última instancia, el dato a partir del cual se levantaba todo el edificio constitucional gaditano

47 GUERRA. Modernidad e independencias, p.175.

48 Diario de Sesiones de las Cortes, 25 de agosto de 1811 (esta última expresión luego se suprimió puesto que ponía en cuestión la permanencia del sistema monárquico, algo que un sector importante de diputados no estaba dispuesto a hacer).

49 Citado por ARTOLA, Miguel. Los orígenes de la España contemporánea. Madrid: Instituto de Estudios Políticos, 1959, p.409 (énfasis agregado). 
y la premisa de la que los nuevos poderes representativos tomaban su legitimidad. ${ }^{50}$ Sólo en las colonias habrá de plantearse la necesidad de crear, en el mismo acto de constitución del orden político, también aquella entidad a la que éste debía representar (la nación).

En efecto, la pregunta fundamental aquí ya no será verdaderamente cómo estaba constituida la nación sino cuál era ésta. Más allá del mayor tradicionalismo o no de las ideas de los actores, la revolución americana producirá así una segunda ruptura al nivel de las problemáticas subyacentes. Comprender cómo se produjo esta inflexión contiene la clave para entender el sentido de la mutación conceptual que Guerra se propone analizar. Pero, para ello, es necesario romper los marcos de la antigua historia de ideas. Seguramente, hacia 1825 los latinoamericanos seguirían pensando no muy distinto a como lo hacían antes de 1810, lo que puede llevar a concluir que, desde el punto de vista de la historia intelectual, entre ambas fechas no cambió gran cosa en América Latina. Esto, sin embargo, no es así. La ruptura del vínculo colonial supuso un quiebre irreversible también al nivel de la historia intelectual. El problema radica, en última instancia, en que las "ideas" no alcanzan a registrar los cambios producidos en las condiciones de su enunciación de los discursos, como habrá de reconfigurarse objetivamente el suelo de problemáticas subyacentes. En definitiva, una historia de los lenguajes políticos se orienta a analizar cómo, más allá de la persistencia de ideas se alteraron las coordenadas conceptuales a partir de las cuales éstas tomaban su sentido, tratar de descubrir en los propios textos las huellas lingüísticas de los cambios de las alteraciones en las condiciones de enunciación de los discursos. No es otro, en fin, el sentido de la revolución metodológica que, como señala Pocock en la cita que sirve de epígrafe al presente trabajo, viene experimentando la disciplina en los últimos años.

\section{BIBLIOGRAFÍA CITADA}

Álvarez Junco, José Mater Dolorosa. La idea de España en el siglo XIX. Madrid: Taurus, 2001.

Annino, Antonio, Luis Castro Leiva y François-Xavier Guerra, comps. De los imperios a las naciones. Iberoamérica. Zaragoza: Ibercaja, 1994.

Argüelles, Agustín. La reforma constitucional de Cádiz. Madrid: ITER, 1970.

Artola, Miguel. Los orígenes de la España contemporánea. Madrid: Instituto de Estudios Políticos, 1959.

50 Para Martínez Marina, su origen data del siglo XII, cuando el pueblo es convocado por primera vez a Cortes. «El pueblo, que realmente es la nación misma y en quien reside la autoridad soberana», dice, «fue llamado a un augusto congreso, adquirió el derecho de voz y voto en las cortes de que había estado privado, tuvo parte en las deliberaciones, y sólo él formaba la representación nacional: revolución política que produxo los más felices resultados y preparó la regeneración de la monarquía. Castilla comenzó en cierta manera á ser una nación». MARINA, Martínez. Discurso sobre el origen de la monarquía, p.133. 
Ávila Palafox, Ricardo, Carlos Martínez Assad y Jean Meyer, coords. Las formas y las políticas del dominio agrario. Homenaje a François Chevalier. Guadalajara: Universidad de Guadalajara, 1992.

Berruezo, María Teresa. La diputación americana en las Cortes de Cádiz. Madrid: Centro de Estudios Constitucionales, 1986.

Blumenberg, Hans. Die Genesis der kopernikanischen Welt. Francfort: Suhrkamp, 1996.

Breña, Roberto. "Un momento clave en la historia política moderna de la América hispana: Cádiz, 1812", manuscrito.

Chiaramonte, José Carlos. El mito de los orígenes en la historiografía latinoamericana, en Cuadernos del Instituto Ravignani 2. Buenos Aires: Instituto de Historia Argentina y Americana "Dr. Emilio Ravignani", 1991.

Chust, Manuel. La cuestión nacional americana en las Cortes de Cádiz (1810-1814). Valencia: UNED / Historia Social / UNAM, 1999.

Diario de Sesiones de las Cortes de Cádiz (1810-1814).

Giménez Fernández, Manuel. Las doctrinas populistas en la independencia de Hispano-América. Sevilla: CSIC, 1947.

Guerra, François-Xavier. Modernidad e independencias. Ensayos sobre las revoluciones hispánicas. México: MAPFRE / F.C.E., 1993.

Jovellanos, Melchor Gaspar de. «Memoria», en Escritos políticos y filosóficos. Barcelona: Folio, 1999.

Martínez Marina, Francisco. Discurso sobre el origen de la monarquía y sobre la naturaleza del gobierno español. Madrid: Centro de Estudios Constitucionales, 1988.

Moreno, Mariano. Escritos políticos y económicos. Buenos Aires: La Cultura Argentina, 1915.

Rieu-Millan, Marie. Los diputados americanos en la Cortes de Cádiz. Madrid: CSIC, 1998.

Sánchez Agesta, Luis. Historia del constitucionalismo español. Madrid: Instituto de Estudios Políticos, 1955.

Skinner, Quentin. The Foundations of Modern Political Thought. Cambridge: Cambridge University Press, 1988.

Terán, Marta y José Antonio Serrano Ortega, eds. La guerra de independencia en la América española. Zamora, Michoacán: El Colegio de Michoacán / Instituto Nacional de Antropología e Historia / Universidad Michoacana de San Nicolás de Hidalgo, 2002.

Varela Suances-Carpegna, Joaquín. La teoría del Estado en los orígenes del constitucionalismo hispánico (Las Cortes de Cádiz). Madrid: Centro de Estudios Constitucionales, 1983. 